\title{
A Igreja dos pobres como nota da Igreja e marca da espiritualidade cristã: uma reflexão a partir de Jon Sobrino e do Papa Francisco
}

\author{
The Church for the poor as a Church Note \\ and mark of Cristian spirituality: \\ a reflection from Jon Sobrino and Pope Francis
}

Antônio Ronaldo Vieira Nogueira

\section{Resumo}

O desejo do Papa Francisco de "uma Igreja pobre e para os pobres" situa-se na mais genuína tradição bíblica e teológica em que o Reino de Deus caracteriza-se pela justiça aos pobres e oprimidos. Essa profunda intuição reapareceu no Concílio Vaticano II, embora não tenha recebido devida atenção, e ganhou importantes desenvolvimentos no Magistério latino-americano e, mais especialmente, na Teologia da Libertação. Esta desenvolveu o tema da Igreja dos pobres, colocando-o como nota da Igreja. Jon Sobrino é um dos maiores expoentes nesse tema. Por isso, nosso trabalho, a partir das reflexões de Jon Sobrino e do Papa Francisco, quer verificar a importância e a base teológica desse tema como nota da Igreja e como marca da espiritualidade cristã. Para isso, precisamos entender, primeiramente, o que significa espiritualidade, assumindo-a como vivência segundo o Espírito de Jesus, seguimento de Jesus; em seguida explicitaremos como a Teologia da Libertação e, especialmente, Jon Sobrino, colocam a Igreja dos pobres como nota da Igreja e como isso aparece na Evangelii Gaudium do Papa Francisco; por fim, falaremos da necessidade de uma nova eclesiologia e espiritualidade voltadas para os pobres, o que se traduz numa Igreja servidora dos pobres. 
Palavras-chave: Igreja dos pobres. Espiritualidade. Jon Sobrino. Papa Francisco.

\begin{abstract}
Pope Francis' desire of "a poor Church and for the poor" it based on a genuine biblical and theological tradition, which the Kingdom of God is characterized for justice toward the poor and oppressed. This profound insight reappeared in II Vatican Council, even if it did not received the needed attention. On the other hand, this theme owned important development in Latin American's Church Teachings, special with the Liberation Theology, which developed this matter and put it as a Note that has Jon Sobrino as it most exponent. Therefore, our paper, from Juan Sobrino and Pope Francis' reflections wish to verify the importance and the theological bases of this theme as a Note for the Church and mark for Cristian spirituality. In this regard, we will try to explain, first, spirituality as a fellowship according Jesus' spirit and discipleship; secondly, we will highlight how Liberation Theology, and specially, Jon Sobrino, putted the Church for the poor as Church Note, pointing out this sensibility in Pope Francis' Evangelli Gaudium; finally we will speak about a need of a new ecclesiology and spirituality which results in a poor Church server.
\end{abstract}

Keywords: Church for the poor. Spirituality. Jon Sobrino. Pope Francis.

\title{
Introdução
}

O Concílio Vaticano II foi um dos maiores e mais importantes da história da Igreja. Nele se depositaram muitas esperanças de que a Igreja pudesse se atualizar e se abrisse ao diálogo. Foi no contexto desse grande evento eclesial que João XXIII fez um discurso no qual resgatou o que ele mesmo chamou de "ponto luminoso": a Igreja dos pobres. Disse o papa: "pensando nos países subdesenvolvidos, a Igreja se apresenta e quer realmente ser a Igreja de todos, em particular, a Igreja dos pobres"1. Isso despertou expectativas por parte de muitos, especialmente das Igrejas do terceiro mundo. O tema não recebeu a devida atenção no Concílio, mas deixou suas marcas, retomadas e aprofundadas

${ }^{1}$ JOÃO XXIII, Papa. "Mensagem radiofônica a todos os fieis católicos, a um mês da abertura do Concílio". In: CONCÍLIO VATICANO II. Mensagens, discursos e documentos. São Paulo: Paulinas, 2007, pp.20-26, letra L. 
pelo Magistério latino-americano, especialmente em Medellín, e também pela teologia da libertação, que desenvolveu o tema da Igreja dos pobres como nota da Igreja. Hoje, o papa Francisco retoma essa intuição com o projeto de uma "Igreja pobre e para os pobres", em consonância com a tradição cristã, na qual o Reino de Deus caracteriza-se como justiça aos pobres e oprimidos.

Por isso, nosso trabalho vai se debruçar sobre o tema da Igreja dos pobres como nota da Igreja e marca da espiritualidade cristã. Primeiro, faremos uma reflexão a respeito do que se entende por espiritualidade cristã e, depois, tendo como referências as reflexões de Jon Sobrino, como representante da teologia da libertação, e do papa Francisco, especialmente a partir da Evangelii Gaudium, queremos perceber como a Igreja dos pobres aparece como nota da Igreja. Por fim, explicitaremos a necessidade de uma nova espiritualidade e eclesiologia voltadas para os pobres, o que se traduz numa Igreja servidora dos pobres.

\section{Espiritualidade cristã como seguimento de Jesus}

Muito se tem falado, nos tempos hodiernos, em espiritualidade, Espírito Santo, vida segundo o Espírito. Cresce cada vez mais o número de movimentos em que se dá grande valor à ação do Espírito, resgatando algo que parece ter ficado esquecido pela Igreja e a Teologia ocidentais. Porém, aparece aqui o problema da separação entre o Espírito e Jesus. Obviamente isso não é dito, mas não é muito difícil perceber que, quando se nomeia normalmente as experiências do Espírito ou frutos dela, tais experiências pouco ou nada têm a ver com aquilo que fez o Espírito em Jesus de Nazaré e os frutos que produziu em sua vida ${ }^{2}$. Por isso, parece necessário explicitar o que significa espiritualidade cristã ${ }^{3}$.

A espiritualidade pode ser definida, grosso modo, como vida segundo o Espírito. No Novo Testamento, o Espírito aparece sempre em estreito vínculo com Jesus Cristo 4 . Disso se pode inferir que não podemos falar de espiritualidade, em âmbito cristão, sem que o Espírito esteja e seja verificado na

\footnotetext{
${ }^{2}$ AQUINO JÚNIOR, F. de. Viver segundo o espírito de Jesus Cristo: espiritualidade como seguimento. São Paulo: Paulinas, 2014, p. 16.

${ }^{3}$ Para um maior aprofundamento da espiritualidade como dimensão humana, cf. Ibidem, pp.16-26.

${ }^{4}$ Há uma série de textos, onde isso se verifica: é Espírito de Cristo (Rm 8,9; Fl 1,19), Espírito do Senhor (2 Cor 3,17), Espírito do Filho (Gl 4,6), sua missão é recordar o que Jesus disse (Jo 14,26), dizer e explicar o que ouviu/recebeu de Jesus (Jo 16,13-14), dar testemunho de Jesus (Jo 16,26).
} 
vida/práxis de Jesus de Nazaré. Desse modo, falar de espiritualidade cristã é "falar da experiência do Espírito de Jesus de Nazaré: viver como Ele viveu e do que Ele viveu, isto é, configurar ou conformar a própria vida à sua vida. Numa palavra: viver segundo seu Espírito"s. Assim, para verificarmos a ação do Espírito, é imprescindível que voltemos à vida/prática de Jesus.

Se a espiritualidade é viver como e do que Jesus viveu, conformando e configurando nossa vida à dele, então, ela consiste no seguimento de Jesus de Nazaré: "A espiritualidade cristã é, necessariamente, uma espiritualidade do

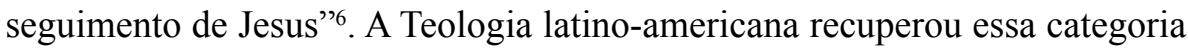
do seguimento como princípio estruturador da vida cristã:

O seguimento, certamente, é o princípio estrutural e hierárquico de toda a vida cristã, segundo o qual podem e devem organizar-se outras dimensões dessa vida (pertença à Igreja, ortodoxia, liturgia, etc.), mas não inversamente. Esse princípio não é outra coisa senão prosseguir na história a estrutura fundamental da vida de Jesus: encarnação, prática e espírito da missão, cruz e ressurreição ${ }^{7}$.

Essa estrutura fundamental da vida de Jesus se dá num mundo bem preciso: o mundo dos pobres e excluídos. Assim, a encarnação com a qual começa a vida cristã não acontece no mundo simplesmente, mas no mundo dos pobres e oprimidos. Também a vida cristã é prática e, contemplando o horizonte da prática de Jesus, então, ela consiste fundamentalmente num amor cristão prático aos milhares de seres humanos que vivem privados da dignidade humana ${ }^{8}$. Com isso, o cristão reproduz também o destino de Jesus: conflito, perseguição e morte. Esse é o modo mais exato de verificar o seguimento a Jesus e, paradoxalmente, gera credibilidade e eficácia porque aproxima dos pobres e sofredores. Quem assim segue a Jesus já participa de

${ }^{5}$ AQUINO JÚNIOR, op.cit., p.28.

${ }^{6}$ ELLACURÍA, I. "Espiritualidade”. In: SAMANES, C. F.; TAMAYO-ACOSTA, J. J. (orgs.). Dicionário de Conceitos Fundamentais do Cristianismo. São Paulo: Paulus, 1999, pp.240-245 (aqui: p.242).

${ }^{7}$ SOBRINO, J. Seguimento. In: SAMANES, C. F.; TAMAYO-ACOSTA, J. J., op.cit., pp.771775. (aqui: p.773).

8 “Uma espiritualidade que não venha de e não vá a uma praxe libertadora do pecado e de suas consequências, não responderia à vida de Jesus. Esta é a grande prática espiritual, isto é, a vida inteira dedicada, a partir dos pobres, onde o pecado, negação do Espírito de vida, desapareça do mundo, para que irrompa, na história, o Reino de Deus, que é o Deus de vida" (ELLACURIA, op.cit., p. 243). 
sua ressurreição e espera, confiante, a plenitude quando "Deus será tudo em todos" (1Cor 14,28). Trata-se de esperança contra toda esperança (cf. Rm $4,18)$; porém, é esperança real, pois se apoia na continuação da vida de Jesus9. É isso, em grandes linhas, o que significa a espiritualidade cristã, enquanto seguimento de Jesus.

\section{A Igreja dos pobres como nota da Igreja na teologia da libertação e em Jon Sobrino}

O tema da Igreja dos pobres faz parte da mais genuína tradição da Igreja em que a Boa Nova do Reino de Deus consiste na justiça aos pobres e oprimidos. Para Ellacuría, “o conceito 'Igreja dos pobres' expressa um elemento essencial da constituição dogmática da Igreja [...], descuidado com frequência na conceitualização e, sobretudo, na prática pastoral da Igreja" ${ }^{10}$.

A princípio, falar de Igreja dos pobres como nota da Igreja poderia levar à pergunta se as notas una, santa, católica e apostólica não são suficientes. Como diz Jon Sobrino, parece ser chocante, mas também necessário, pois falar de outra nota introduz algo muito fundamental: "uma Igreja verdadeira é, antes de tudo, uma Igreja que 'se parece com Jesus', e todos intuímos que sem alguma semelhança com ele não seremos sua Igreja nem esta se fará notar como Igreja de Jesus" ${ }^{\prime 1}$. Assim, o fundamento da reflexão da Igreja dos pobres como nota da Igreja está no consenso apresentado pelos estudos bíblicos e cristológicos recentes: a relação intrínseca entre Jesus, o Reino e os pobres ${ }^{12}$.

Com palavras de Isaías $(61,1-2)$, Jesus apresenta sua missão de anúncio e realização do Reino, na força do Espírito Santo (cf. Lc 4,18-19). Ele não fez de si o centro da pregação e missão, mas o Reino de Deus: "o tema central da

\footnotetext{
${ }^{9}$ Cf. SOBRINO, Seguimento, In: SAMANES, C. F.; TAMAYO-ACOSTA, J. J., op.cit., pp. 773-774.

${ }^{10}$ ELLACURÍA, I. "Pobres". In: Escritos Teológicos II. San Salvador: UCA, 2000, pp. 171-192. (aqui: p. 189) (tradução nossa). Não retomaremos a história recente da formulação da Igreja dos pobres. Para uma abordagem dessa história, cf. AQUINO JÚNIOR, op.cit., pp. 119-135. ${ }^{11}$ SOBRINO, J. "A Igreja Samaritana e o Princípio Misericórdia". In: O Principio Misericórdia: Descer da Cruz os Povos Crucificados. Petrópolis: Vozes, 1994, pp. 31-45. (aqui: p. 31).

${ }^{12}$ Aquino Júnior apresenta uma série bibliográfica de estudos bíblicos e cristológicos que são consensuais em que não se pode falar de Jesus Cristo senão e em função do reinado de Deus (Cf. AQUINO JÚNIOR, op.cit., p. 141).
} 
proclamação pública de Jesus foi o reinado de Deus"13. No centro do Reino de Deus está a justiça aos pobres e oprimidos, garantindo e defendendo seus direitos ${ }^{14}$. É o que expressa Joachim Jeremias: o "traço decisivo" do Reino de Deus está "na oferta de salvação feita por Jesus aos pobres"15. Mais: "O Reino pertence unicamente aos pobres" ${ }^{16}$. Assim, se a Igreja é a comunidade dos discípulos de Jesus, que o segue e deve ter a mesma estrutura de sua vida/ práxis, então pode e deve ser constituída como Igreja dos pobres. Essa é sua nota constitutiva e configurativa:

Igreja dos pobres não significa [...] uma parte da Igreja que se dedica preferencialmente aos pobres, senão uma nota constitutiva e configurativa de toda a Igreja, de sorte que esta ou é dos pobres ou deixa de ser a Igreja verdadeira e santa querida por Deus. A Igreja deve ser una, santa católica, apostólica e pobre, porque a Igreja se configura desde o reino anunciado por Jesus e este, antes de ser católico e apostólico, é uno, santo e dos pobres. Igreja dos pobres significa fundamentalmente a Igreja inteira de tal modo constituída e configurada que os pobres tenham nela o lugar preferencial que Jesus quis que tivessem ${ }^{17}$.

Isso não é algo marginal: "trata-se [...] de uma questão dogmática, de uma verdade fundamental da revelação e da fé cristãs, de uma questão de ortopráxis eclesial e de ortodoxia teológica, sem a qual uma 'Igreja' pode ser tudo, menos Igreja de Jesus Cristo. [...] Essa nota é tão essencial e fundamental na Igreja quanto as demais e é tão antiga quanto elas [...]"18. A Igreja dos pobres é, nas palavras de Jon Sobrino, "[...] uma ruptura com outras formas tradicionais de ser Igreja e [...] [nela] aparece uma plenitude maior, uma maior autenticidade da Igreja" ${ }^{\prime 19}$. Ele analisa teologicamente a Igreja dos pobres a partir de sua origem no Novo Testamento e a verifica através das quatro notas tradicionais.

${ }^{13}$ JEREMIAS, J. Teologia do Novo Testamento. São Paulo: Hagnos, 2008, p. 160.

${ }^{14}$ Cf. AQUINO JÚNIOR, op.cit., p. 141.

${ }^{15}$ JEREMIAS, op.cit., p. 176.

${ }^{16}$ Ibidem, p. 187.

${ }^{17}$ ELLACURÍA, "Pobres". In: op.cit., p. 189 (tradução nossa).

${ }^{18}$ AQUINO JÚNIOR, F. de. "Uma Igreja pobre e para os pobres". Convergência 49 (2014), pp. 349-364 (aqui: p. 352).

${ }^{19}$ SOBRINO, J. Ressurreição da Verdadeira Igreja: os pobres, lugar teológico da eclesiologia. São Paulo: Loyola, 1982, p. 94. 
A primeira coisa a se explicitar é o tipo de Igreja que surge no Novo Testamento e sua relação com o Ressuscitado: "A Igreja segundo o NT surge certamente pelo fato da ressurreição de Cristo, mas o que surge está em correspondência [...] com uma vida concreta solidária com os pobres e a seu serviço. [...] Esta correspondência é melhor expressa por aquilo que se entende por 'Igreja dos pobres' [...]"20. Essa é a tese teológica. Enquanto tese histórica, recolhem-se afirmações no Novo Testamento que dão conta de uma Igreja pobre, formada por pessoas pobres e procurada como esperança dos pobres: "Em nível histórico [...] se o povo tendia para a Igreja é porque tinha necessidade de uma esperança e via na Igreja nascente uma esperança para ele. Os pobres, os escravos, os desprezados, viam algo nesse Jesus ressuscitado em profunda correlação com sua atual situação de miséria" ${ }^{21}$.

A Igreja que surge no Novo Testamento é, portanto, a Igreja dos pobres, na qual eles são seu princípio de estruturação, organização e missão: "quando os pobres se tornam o centro da Igreja, eles dão direção e sentido a tudo o que legitimamente [...] e necessariamente [...] constitui a realidade concreta da Igreja: sua pregação e ação, suas estruturas administrativas, culturais, dogmáticas etc. Os pobres [...] são fonte de 'concretização' cristã de toda a realidade eclesial" 22 . Agora é preciso verificar como essa nota influencia e determina as notas tradicionais para se verificar como verdadeira Igreja.

A unidade da Igreja implica uma origem, um só Deus, um só Senhor, um só batismo, um só Espírito. Na Igreja dos pobres esse princípio se concretiza ${ }^{23}$. As características da unidade da Igreja dos pobres são: 1) Não há barreira entre grupos: ela é quebrada pela solidariedade na forma de "levar-se mutuamente", de ser "um" corpo eclesial e assim ir fazendo a Igreja "una". 2) Admite-se e exige-se a participação plural da totalidade da Igreja, aceitando a hierarquia como guia, o ministério sacerdotal e a vida religiosa, mas admitindo novos ministérios e novas formas de organização eclesial. 3) Quanto aos mecanismos de unificação interna, como os sacramentos e o serviço da hierarquia à unidade: quando se celebra um martírio ou uma celebração camponesa

${ }^{20}$ Ibidem, pp. 98-99.

${ }^{21}$ Ibidem, pp. 99-100.

${ }^{22}$ Ibidem, p. 103.

23 "Existe um só Senhor, Jesus Cristo [...], crucificado, servo de Javé e ressuscitado; existe um só Deus, que quer a vida dos homens, escuta o clamor dos oprimidos, morre com eles na história e mantém sempre vivos os gemidos de parto de uma nova criação; existe um só Espírito, renovador da história, doador de vida e que fala pelos profetas de outrora e pelos atuais" (Ibidem, p. 111) 
se consegue atrair os cristãos que não são sociologicamente pobres (coisa muito rara na celebração de "ricos"); além disso, a Igreja dos pobres reconhece, admite e exige que o Bispo seja cabeça unificadora da diocese, quando ouve seu povo e este reconhece nele sua própria voz e a disposição a dar a vida pelas ovelhas. Os pobres têm ainda a capacidade de colocar a Igreja no rumo certo, mostrando o que sejam união e desunião: "lembram-lhe que a unidade imediata [...] está sujeita à missão. E lembram-lhe, por último, que a unidade é uma dimensão escatológica que irá se realizando na história através do conflito e não se construirá buscando-a em si mesma com base em mecanismos internos eclesiais de unidade"24.

A santidade é a primeira nota, cronológica e logicamente, pois a Igreja deve ser sinal de salvação, sacramento histórico do amor de Deus e seria contraditório se não fosse santa, embora tenha sempre se reconhecido que a Igreja é santa e pecadora. Na Igreja dos pobres, a santidade e o pecado são concretizados. A santidade consiste ' [...] em manter o 'sim' de Deus ao mundo do amor e da graça e manter o 'não' de Deus ao mundo do pecado" ${ }^{25}$. Já o pecado é o que dá morte ao homem e o pecado fundamental da Igreja foi ter colaborado com o pecado do mundo, sendo conivente ou até mesmo justificando- ${ }^{26}$. Sobrino resume assim a santidade da Igreja e que se verifica na Igreja dos pobres:

A Igreja santa é [...] a Igreja que se encarna na história à imitação de Jesus, numa situação determinada, com destinatários parciais a quem procura salvar. É a que percorre o caminho de Jesus, caminho de solidariedade e fraternidade, caminho de conflito e polêmica com o poder. E sobretudo é a Igreja que vive o mistério pascal de Jesus. É a Igreja que morre quando os pobres nela, e os que com ela se solidarizam são mortos pelo poder, e que morre também quando eclesialmente é ignorada e atacada. E é também a Igreja que ressuscita permanentemente porque a morte não faz desaparecer a esperança, e o risco não paralisa a prática do amor. A Igreja dos pobres é hoje a Igreja mártir que historicamente reproduz a vida e a páscoa de Jesus ${ }^{27}$.

\footnotetext{
${ }^{24}$ Ibidem, p. 114.

${ }^{25}$ Ibidem, p. 116.

${ }^{26}$ Cf. Ibidem, pp. 116-117.

${ }^{27}$ Ibidem, p. 119.
} 
A catolicidade designa a correta relação entre igrejas locais com a Igreja universal, a correta inserção da igreja local na Igreja universal e a correta inserção da Igreja na pluralidade de igrejas cristãs e na comunidade universal da humanidade ${ }^{28}$. A parcialidade dos pobres e para os pobres fez a Igreja na América Latina descobrir seu caráter "local" e sua dimensão "universal". Ela redescobriu sua identidade e consciência históricas; nela se desenvolveu uma reflexão original e própria, a teologia da libertação; possibilitou-se, ainda, um magistério próprio que, com criatividade, concretiza o magistério universal na realidade latino-americana ${ }^{29}$. É ainda através da consciência de ser igreja local que se está criando consciência do caráter católico e universal da Igreja: a igreja latino-americana criou consciência de igreja local sem cisma ou heresia com relação a outras igrejas e em se saber fazendo parte de uma igreja mais ampla que vive semelhantemente a pobreza e o cativeiro e sente o mesmo desejo de libertação. Também, a partir da perspectiva dos pobres, a catolicidade se entende melhor como ajuda mútua, num processo de solidariedade entre as diversas Igrejas locais. Isso também se pode estender a outras religiões e à comunidade humana: "Aí onde irrompem os pobres 'localmente' e se faz uma opção por eles, os diversos grupos cristãos e humanos afirmam a própria identidade e se abrem à universalidade da pobreza e à universalidade da libertação" ${ }^{30}$.

A apostolicidade da Igreja implica duas coisas: ela deve remontar aos Apóstolos, à origem da fé, no sentido cronológico; deve manter hoje a estrutura apostólica - ser enviada, ser missionária. A Igreja dos pobres desenvolveu o apostolado nos dois sentidos e o concretizou. $\mathrm{O}$ apostolado tem primazia lógica sobre a Igreja instituição e suas características: a Evangelii Nuntiandi afirma (n.14) que a evangelização constitui vocação e identidade mais profunda da Igreja e que as realidades ad intra - oração, escuta da palavra, caridade fraterna, pão compartilhado - "não tem pleno sentido senão quando se converte em testemunho, provoca admiração e a conversão se torna pregação e anúncio da Boa Nova" (n.15) ${ }^{31}$. A Igreja dos pobres é missionária, e isso se dá pela presença dos

\footnotetext{
${ }^{28}$ Cf. Ibidem, p. 119.

29 “[...] é o próprio povo latino-americano que está tomando consciência de seu ser Igreja, sem que para isso deva deixar de ser latino-americano [...]. Pela primeira vez pode-se ser cristão na América Latina sem pedir emprestada a eclesialidade de outras igrejas. Pela primeira vez existe uma igreja verdadeiramente "local'" (Ibidem, p. 121).

${ }^{30}$ Ibidem, p. 124.

${ }^{31}$ Cf. Ibidem, p. 126.
} 
pobres nela. As características dessa missão conforme a Evangelii Nutiandi se realizam e se concretizam na Igreja dos pobres: 1) Os pobres tornam presente historicamente a diferença entre a realidade histórica e o anúncio da Boa Nova e exigem objetivamente que a Igreja se constitua nesse anúncio e que precisa pôr-se a serviço dele. 2) Na Igreja dos pobres, a pregação do mistério do mal aparece concretamente na união entre anúncio e denúncia. 3) O testemunho de vida do apóstolo, fortaleza na perseguição, disponibilidade em dar a vida e martírio, também estão presentes da Igreja dos pobres e seus inúmeros mártires. 4) A missão da Igreja consiste em realizar o que anuncia, em fazer que se torne Boa realidade a Boa Notícia: "Essa notícia só será boa na medida em que se realizar a libertação dos oprimidos"32. 5) Os pobres são os destinatários privilegiados da Boa Nova. Por isso, a verdadeira Igreja se constitui através da missão e a direção cristã dessa missão é oferecida pelos pobres ${ }^{33}$.

Vemos que a Igreja dos pobres cumpre os critérios estabelecidos pelas quatro notas tradicionais. Mais: ela também as concretiza na história, constituindo-se como verdadeira Igreja de Jesus. Podemos perceber que esse ser dos pobres não só é nota da Igreja, mas é nota fundamental pela qual as outras se verificam e se atualizam. Com isso, não se quer dizer que a Igreja dos pobres não possa ser contaminada com pecados e erros, mas o que se quer dizer é que ela é hoje, estruturalmente, a forma verdadeira de ser Igreja de Jesus ${ }^{34}$.

\section{O projeto da Igreja pobre e para os pobres no Papa Francisco}

O projeto de uma "Igreja pobre e para os pobres", tornou-se o centro das preocupações, orientações pastorais e é uma marca do ministério de Francisco. Seu nome e muitas de suas afirmações e gestos indicam esse projeto: pobre no jeito de ser (vestimentas e expressões simbólico-rituais) e comprometida com os pobres (proximidade física e prioridade pastoral) ${ }^{35}$. Uma análise pano-

\footnotetext{
${ }^{32}$ ESCUDERO FREIRE apud SOBRINO, Ressurreição da Verdadeira Igreja, p. 128.

${ }^{33}$ Cf. SOBRINO, Ressurreição da Verdadeira Igreja, p. 129.

${ }^{34}$ Cf. Ibidem, p. 133.

${ }^{35}$ Cf. AQUINO JÚNIOR, F. de. "Uma Igreja pobre e para os pobres". Convergência 49 (2014), p. 354. Num dos primeiros discursos, Francisco explicou que a escolha do nome se deu após a frase "não te esqueças dos pobres!" do Cardeal Hummes como cumprimento pela escolha do novo papa; isso o fez remontar a Francisco de Assis (cf. FRANCISCO, Papa. "Encontro com os representantes dos meios de comunicação social". Discurso do Santo Padre Francisco. Roma, 16 de março de 2013. Disponível em: <http://w2.vatican.va/content/ francesco/pt/speeches/2013/ march/documents/pa pa-francesco_20130316_rappresentanti-media.html>. Acesso em 15 de
} 
râmica da Evangelii Gaudium ${ }^{36}$ ajuda a perceber como ele propõe teológica e pastoralmente a Igreja dos pobres.

Uma primeira e fundamental afirmação é que "evangelizar é tornar o Reino de Deus presente no mundo" (EG 176). Realizar esse Reino é dirigir-se aos destinatários privilegiados: "hoje e sempre, 'os pobres são os destinatários privilegiados do Evangelho' [Bento XVI], e a evangelização dirigida gratuitamente a eles é sinal do Reino que Jesus veio trazer" (EG 48). Percorrendo vários textos da Escritura e da Tradição, Francisco constata que Deus sempre ouve o clamor dos pobres (cf. EG 187), os pobres ocupam lugar preferencial no coração de Deus (cf. EG 197) de modo que "todo o caminho da nossa redenção está assinalado pelos pobres" (EG 197). Por isso, permanecer "surdos" ao clamor dos pobres e não solidarizar-se com eles implica em estar "fora da vontade do Pai e do seu projeto" e "influi diretamente sobre a nossa relação com Deus" (EG 187). Se é assim no coração de Deus, essa deve ser também a opção da Igreja: "Inspirada por tal preferência, a Igreja fez uma opção pelos pobres, entendida como uma 'forma especial de primado na prática da caridade cristã, testemunhada por toda a Tradição da Igreja' [João Paulo II]". Recorrendo e fazendo sua a afirmação de Bento XVI, diz Francisco: "esta opção 'está implícita na fé cristológica naquele Deus que Se fez pobre por nós, para enriquecer-nos com sua pobreza'. Por isso, desejo uma Igreja pobre para os pobres" (EG 198).

A opção pelos pobres aparece, então, como categoria teológica: "Para a Igreja a opção pelos pobres é mais uma categoria teológica que cultural, sociológica ou filosófica" (EG 198). Como afirma Aquino Júnior, "a opção pelos pobres pertence ao coração do Evangelho do reinado de Deus e, enquanto tal, ela é constitutiva (e não meramente consecutiva e opcional!) da fé cristã". É ainda nesse sentido, ressalta Aquino Júnior, que se pode "[...] compreender o fato de Francisco falar, às vezes, simplesmente de 'opção pelos pobres' (EG 195, 198), sem os receios, os escrúpulos e as ponderações que [...] se traduziam numa série de adjetivos [...] que, mais que explicar e precisar seu sentido, terminavam por enfraquecê-la e torná-la irrelevante na vida da Igreja" ${ }^{37}$. Essa categoria é tão

maio de 2015). Seu nome representa, portanto, um projeto de Igreja (Cf. CAVACA, O. "Uma eclesiologia chamada Francisco: estudo da eclesiologia do papa Francisco a partir da Evangelii Gaudium”. Revista de Cultura Teológica 22 (2014), pp.15-34. (aqui: pp. 16-17)).

${ }^{36}$ FRANCISCO, Papa. Exortação Apostólica Evangelii Gaudium sobre o anúncio do Evangelho no mundo atual. São Paulo: Paulinas, 2013. Doravante, ela será citada no texto com a sigla EG. ${ }^{37}$ AQUINO JÚNIOR, F. de. "Uma Igreja pobre e para os pobres". Convergência 49 (2014), pp. 355-356. 
clara que Francisco chama a atenção para quaisquer tentativas de relativizá-la ou enfraquecê-la: "É uma mensagem tão clara, tão direta, tão simples e eloquente que nenhuma hermenêutica eclesial tem o direito de relativizar. A reflexão da Igreja sobre esses textos não deveria ofuscar nem enfraquecer o seu sentido exortativo, mas antes ajudar a assumi-los com coragem e ardor" (EG 194).

Sendo categoria teológica, a opção pelos pobres ou a Igreja dos pobres é algo que não deve ser esquecido na eclesiologia: ““[...] o serviço da caridade é uma dimensão constitutiva da missão da Igreja e expressão irrenunciável da sua própria essência' [Bento XVI]. Assim como a Igreja é missionária por natureza, também brota inevitavelmente dessa natureza a caridade efetiva para com o próximo, a compaixão que compreende, assiste e promove" (EG 179). Assim, o "critério-chave de autenticidade" dado pelos Apóstolos a Paulo sobre sua missão (que não se esquecesse dos pobres (cf. Gl 2,10)) é apresentado por Francisco como tendo "uma grande atualidade" e "[...] sinal que nunca deve faltar: a opção pelos últimos, por aqueles que a sociedade descarta e lança fora" (EG 195).

Dessa maneira, a opção pelos pobres "deriva da nossa fé em Jesus Cristo" (EG 186) e "deriva da própria obra libertadora da graça em cada um de nós" (EG 188). Se há, portanto, "um vínculo indissolúvel entre a nossa fé e os pobres" (EG 48), então os cristãos e as comunidades "são chamados, em todo lugar e circunstância, a ouvir os clamores dos pobres" (EG 191), sendo "instrumentos de Deus a serviço da libertação e promoção dos pobres" (EG 187).

Mas poderíamos nos perguntar quem são os pobres dos quais Francisco fala $^{38}$. Na EG, ele cita algumas novas formas de pobreza (EG 210-215), de modo que, falar de pobres e de periferia, significa falar "dos excluídos (econômica, social, política e culturalmente etc.), dos pequenos, dos que sofrem, enfim 'dos mais frágeis da terra' [EG 209]. Esses, precisamente, têm que estar no centro das preocupações e prioridades pastorais da Igreja" 39 . Por isso, é preciso agir: Francisco apresenta algumas indicações e exigências da opção pelos pobres ${ }^{40}$. Como pressuposto irrenunciável, retoma a contribuição

\footnotetext{
${ }^{38}$ Segundo Aquino Júnior, "a expressão 'pobre' tem um sentido bastante amplo para Francisco, mas não tão amplo a ponto de, cinicamente, incluir-nos a todos, como se todos fôssemos pobres. Isso, além de encobrir as injustiças e desigualdades sociais e falsificar a realidade, terminaria, na prática, negando a opção pelos pobres. Afinal, se somos todos pobres, a opção pelos pobres é opção por todos. E quando todos se tornam prioridade, ninguém mais é prioridade" (Ibidem, p. 357).

${ }^{39}$ Ibidem, p. 357.

${ }^{40}$ Ibidem, pp. 358-361.
} 
da Igreja latino-americana para o conjunto da Igreja: a opção pelos pobres "envolve tanto a cooperação para resolver as causas estruturais da pobreza e promover o desenvolvimento integral dos pobres, como os gestos mais simples e diários de solidariedade para com as misérias muito concretas que encontramos" (EG 188, grifo nosso). As diretrizes são: 1) proximidade física dos pobres e esforço para socorrê-los em necessidades imediatas (cf. EG 187); 2) cuidado espiritual e abertura para perceber seu potencial evangelizador (cf. EG 198); 3) vivência e fortalecimento da cultura da solidariedade, que "supõe a criação e uma nova mentalidade que pense em termos de comunidade, de prioridade da vida de todos sobre a apropriação dos bens por parte de alguns" (EG 188); 4) enfrentamento das causas estruturais da pobreza e injustiça no mundo, dizendo não a uma "economia da exclusão" (cf. EG 53), à "nova idolatria do dinheiro" (cf. EG 55), a "um dinheiro que governa em vez de servir" (cf. EG 57) e à "desigualdade social que gera violência" (cf. EG 59).

Concluindo, é preciso enfatizar que essa missão é tarefa de todos: "ninguém deveria dizer que se mantém longe dos pobres, porque as suas opções de vida implicam prestar mais atenção a outras incumbências" (EG 201). Por isso, "qualquer comunidade da Igreja, na medida em que pretender subsistir tranquila sem se ocupar criativamente nem cooperar de forma eficaz para que os pobres vivam com dignidade e haja inclusão de todos [...] facilmente acabará submersa pelo mundanismo espiritual, dissimulado em práticas religiosas, reuniões infecundas ou discursos vazios" (EG 207).

\section{A modo de conclusão: nova espiritualidade e eclesiologia voltadas para os pobres}

Vimos que a espiritualidade consiste no seguimento de Jesus para reproduzir, no hoje de nossa história, sua vida/práxis, guiados pelo mesmo Espírito e produzindo os frutos que esse Espírito produziu em sua vida. Se a vida/práxis de Jesus de Nazaré foi guiada pelo anúncio do Reino, enquanto justiça aos pobres e oprimidos, esse deve ser também o conteúdo da verdadeira espiritualidade cristã, seja ela pensada em termos pessoais ou em termos comunitários. Assim, a Igreja, comunidade dos discípulos de Jesus, deve se deixar guiar pelo mesmo Espírito, anunciando e realizando o Reino de Deus na decidida opção pelos pobres.

Assim também, a Igreja verdadeira é aquela que se parece mais com Jesus, reproduzindo a estrutura fundamental de sua vida. Essa estrutura, para Sobrino, é a misericórdia: a misericórdia primigênia de Deus é a que aparece historizada 
na prática e na mensagem de Jesus, é o que configura sua vida e sua missão e provoca seu destino; é ainda o que configura sua visão de Deus e do ser humano. Essa misericórdia, a partir da ação de Deus e de Jesus, é entendida como "amor práxico que surge perante o sofrimento alheio injustamente infligido para erradicá-lo, por nenhum outro motivo além da própria existência desse sofrimento e sem poder apresentar nenhuma desculpa para não fazê-lo"41.

Assim, a verdadeira Igreja de Jesus é a que se deixa reger pelo mesmo princípio misericórdia. Nesse sentido, "o lugar da Igreja é o ferido no caminho conhecida ou não, física e geograficamente, este ferido com o mundo intra-eclesial -; o lugar da Igreja é 'o outro', a alteridade mais radical do sofrimento alheio, sobretudo quando é em massa, cruel e injusto"42. E, por causa disso, a Igreja será perseguida: "Neste mundo são aplaudidas ou toleradas 'obras de misericórdia', mas não se tolera uma Igreja configurada pelo 'princípio misericórdia', o qual a leve a denunciar os salteadores que produzem vítimas, a desmascarar a mentira com que cobrem a opressão e a animar as vítimas a se libertarem deles"43. Mas isso é critério importante para saber se a Igreja verdadeiramente se deixa guiar pelo princípio estruturador da vida de Jesus: a misericórdia.

Finalmente é preciso que se diga que falar do princípio misericórdia, como o entende Jon Sobrino, é falar da opção pelos pobres e falar de Igreja da misericórdia é falar de Igreja dos pobres. Também não se pode esquecer que a misericórdia é uma bem-aventurança e, como tal, deve ser vivida com alegria. Por isso, a Igreja é chamada a transmitir a alegria que está declarada em sua carta magna, as bem-aventuranças, dentre elas a misericórdia. A Igreja da misericórdia é a que se faz notar hoje, e de maneira bem específica, com credibilidade: "Uma Igreja da misericórdia consequente, em vão buscará credibilidade por outros meios. Entre os cansados da fé, os agnósticos e os descrentes, essa Igreja tornará pelo menos respeitável o nome de Deus, e este não será blasfemado pelo que a Igreja faz. Entre os pobres desse mundo essa Igreja suscitará aceitação e agradecimento". Por isso, "uma Igreja da misericórdia consequente é a que se faz notar no mundo de hoje, e se faz notar 'como Deus manda'. Por isso a misericórdia consequente é 'nota' da verdadeira Igreja de Jesus" $"$.

${ }^{41}$ SOBRINO, J. O Princípio-Misericórdia: Descer da cruz os povos crucificados. Petrópolis: Vozes, 1994, p. 35.

${ }^{42}$ Ibidem, p. 39.

${ }^{43}$ Ibidem, p. 42.

${ }^{44}$ Ibidem, p. 45. 


\section{Referências bibliográficas}

AQUINO JÚNIOR, F. de. Viver segundo o espirito de Jesus Cristo: espiritualidade como seguimento. São Paulo: Paulinas 2014.

AQUINO JÚNIOR, F. de. "Uma Igreja pobre e para os pobres". Convergência 49 (2014), pp.349-364.

CAVACA, O. "Uma eclesiologia chamada Francisco: estudo da eclesiologia do papa Francisco a partir da Evangelii Gaudium". Revista de Cultura Teológica 22 (2014), pp.15-34.

ELLACURÍA, I. "Pobres". In: Escritos Teológicos II. San Salvador: UCA, 2000, pp.171-192.

ELLACURÍA, I. "Espiritualidade”. In: SAMANES, C. F.; TAMAYO-ACOSTA (orgs.). Dicionário de Conceitos Fundamentais do Cristianismo. São Paulo: Paulus, 1999, pp.240-245.

FRANCISCO, Papa. Exortação Apostólica Evangelii Gaudium sobre o anúncio do Evangelho no mundo atual. São Paulo: Paulinas, 2013.

FRANCISCO,Papa. "Encontro com os representantes dos meios de comunicação social". Discurso do Santo Padre Francisco. Roma, 16 de março de 2013. Disponível em: $<\mathrm{http}$ :/w2.vatican.va/content/francesco/pt/speeches/2013/ march/documents/papa-francesco_20130316_rappresentanti-media. html>. Acesso em 15 de maio de 2015.

JEREMIAS, J. Teologia do Novo Testamento. São Paulo: Hagnos, 2008.

JOÃO XXIII, Papa. "Mensagem radiofônica a todos os fieis católicos, a um mês da abertura do Concílio". In: CONCÍLIO VATICANO II. Mensagens, discursos e documentos. São Paulo: Paulinas, 2007, pp.20-26.

SOBRINO, J. Ressurreição da Verdadeira Igreja: os pobres, lugar teológico da eclesiologia. São Paulo: Loyola, 1982.

SOBRINO, J. "A Igreja Samaritana e o Princípio Misericórdia". In: O Princípio Misericórdia: Descer da Cruz os Povos Crucificados. Petrópolis: Vozes, 1994, pp.31-45.

SOBRINO, J. "Seguimento". In: SAMANES, C. F.; TAMAYO-ACOSTA (orgs.). Dicionário de Conceitos Fundamentais do Cristianismo. São Paulo: Paulus, 1999, pp.771-775. 
Antônio Ronaldo Vieira Nogueira

Mestrando em Teologia Sistemática pela Faculdade Jesuíta de Filosofia e Teologia (FAJE)

Apoio: CAPES

Belo Horizonte / MG - Brasil

e-mail: antonio_ronaldoa@hotmail.com

Recebido em: 21/05/15

Aprovado em: 25/06/15 